\title{
Diet-induced obesity promotes murine gastric cancer growth through a nampt/sirt1/c-myc positive feedback loop
}

\author{
HAI-JUN LI ${ }^{*}{ }^{*}$, XIANG-MING CHE $^{1 *}$, WEI ZHAO ${ }^{1}$, SHI-CAI HE ${ }^{1}$, \\ ZHENG-LIANG ZHANG ${ }^{2}$, RUI CHEN ${ }^{1}$, LIN FAN ${ }^{1}$ and ZONG-LIANG JIA ${ }^{1}$ \\ ${ }^{1}$ Department of General Surgery, First Affiliated Hospital of Medical College of Xi'an Jiaotong University, \\ Xi'an, Shaanxi 710061; ${ }^{2}$ Department of Emergency, Second Affiliated Hospital of Medical College \\ of Xi'an Jiaotong University, Xi'an, Shaanxi 710004, P.R. China
}

Received June 18, 2013; Accepted August 2, 2013

DOI: $10.3892 /$ or.2013.2678

\begin{abstract}
Obesity increases the risk of gastric cancer and may promote its growth, as was recently demonstrated by our novel in vivo mouse model. However, the underlying mechanisms of this correlation remain unclear. The purpose of this study was to investigate the precise effects of obesity on gastric cancer growth and to elucidate the potential molecular mechanisms. Diet-induced obese mice were insulin-resistant, glucose-intolerant and had high serum visfatin concentration. In the subcutaneous mouse model, tumors were more aggressive in diet-induced obese mice compared with lean mice. Tumor weights showed a significant positive correlation with mouse body weights, as well as serum insulin and visfatin concentrations. Immunohistochemical staining showed that the expression levels of iNampt, Sirt1 and c-MYC proteins were upregulated in the subcutaneous tumors from obese mice compared to those from lean animals. Furthermore, obesity not only prompted significantly murine forestomach carcinoma cell migration, proliferation, but also affected cellular apoptosis and cell cycle by endocrine mechanisms. These were associated with increased expression of the pro-survival nampt/sirt1/c$m y c$ positive feedback loop confirmed by RT-PCR and western blotting. These results suggested that diet-induced obesity could promote murine gastric cancer growth by upregulating the expression of the nampt, sirtl and $c$-myc genes.
\end{abstract}

\section{Introduction}

Gastric cancer is a lethal malignant tumor which accounts for $10 \%$ of all types of invasive cancer in human beings,

Correspondence to: Professor Zong-Liang Jia, Department of General Surgery, First Affiliated Hospital of Medical College of Xi'an Jiaotong University, Xi'an, Shaanxi 710061, P.R. China

E-mail: hj10001@stu.xjtu.edu.cn

*Contributed equally

Key words: gastric cancer, obesity, nampt, sirtl, c-myc particularly in Asia (1); it is also the second leading cause of cancer-related mortality $(2,3)$. Due to the aggressiveness of gastric cancer biology and the limitation of current treatment with advanced disorders, it is critical to elucidate the mechanisms of gastric cancer growth and to identify novel targets for the urgently needed adjuvant therapies.

Obesity, a worldwide epidemic (4), is associated with an increased risk of various malignant tumors such as colon cancer (5) and breast cancer (6). A marked decline in distal gastric cancer was noted, and the incidence of proximal gastric cancer has increased, which may be associated with obesity (7). A meta-analysis demonstrated that the body mass index is closely related to the risk of gastric cancer, particularly in cardia gastric cancer (8).

Adipokines and other growth factors secreted in the context of obesity may enhance cancer cell survival and solid tumor growth (9). The new adipokine, nicotinamide phosphoribosyltransferase (Nampt) was originally described as pre-B-cell colony-enhancing factor (PBEF) promoting early B cell proliferation (10), and attracted considerable interest after it was reported to function as an insulin-mimetic adipokine termed visfatin secreted by visceral fat (11). Nampt has two different forms: intracellular Nampt (iNampt) and extracellular Nampt (eNampt, also known as visfatin) (12). iNampt functioning as an enzyme involved in the $\mathrm{NAD}^{+}$salvage pathway was significantly overexpressed in the genesis of numerous types of cancer, such as colorectal (13), breast (14) and gastric cancer (15). The expression level of visfatin increases with the increase of obesity. Visfatin contributes to a general proinflammatory state in the periphery, and may well prove to be an important mechanistic link in the network of factors affecting obesity-associated tumor growth. Visfatin also acted as an NAD biosynthetic enzyme similar to iNampt (16).

Silent mating-type information regulation 2 homologue 1 (Sirt1) functions as an $\mathrm{NAD}^{+}$dependent histone deacetylase (17) and plays an important role in cell survival under genotoxic and oxidative stress by deacetylating key cell cycle proteins and apoptosis regulatory molecules, such as P53 $(18,19)$. Previous studies have demonstrated that Sirt1 is upregulated in numerous types of human and mouse malignancies including human colon cancer (20) and mouse pulmonary adenocarcinoma (21), which may be involved in carcinogen- 
esis through its antiapoptotic activity (22). Upregulated Sirt1 inactivates P53 by deacetylation (21), and this allows cells with damaged DNA to proliferate and subsequently prompts tumor development (23). c-MYC is the key molecule in a transcription factor network that regulates cellular proliferation, apoptosis and cell differentiation $(24,25)$. Deregulation of c-MYC activity has been implicated in the carcinogenesis of the majority of cancer cases, and its inhibition represents a possible alternative to current cancer therapies (26). A recent study revealed the existence of the positive feedback loop among the c-MYC oncoprotein, the iNampt enzyme and the Sirtl deacetylase (27). Thus, obesity may correlate with gastric cancer growth via a nampt/sirt1/c-myc positive feedback loop.

Currently, limited fundamental studies have been performed regarding the mechanisms by which obesity affects gastric cancer growth. We recently characterized a murine in vivo gastric cancer model in the context of obesity, and found that diet-induced obese mice with high serum visfatin, insulin and glucose levels were insulin-resistant and glucose-intolerant. Furthermore, subcutaneous injected tumors grew faster and larger in obese mice than in lean mice. Tumor weights showed a significantly positive correlation with mouse body weights. In addition, the histological analysis demonstrated that adipocytes within tumors from obese mice were significantly larger than those from lean mice (28). Using this novel in vivo mouse model, we sought to investigate the underlying mechanism of gastric cancer growth under conditions of obesity.

\section{Materials and methods}

Cell culture. The cancer cell line used in this study, murine forestomach carcinoma cell line (MFC), was established in the Chinese Academy of Medical Sciences (29), and purchased from the Type Culture Collection of the Chinese Academy of Sciences, Shanghai, China. MFC was cultured in RPMI-1640 medium (Cellgro, Herndon, VA, USA) containing 10\% (v/v) heat-inactivated fetal bovine serum (Valley Biomedical, Winchester, VA, USA), penicillin (100 U/ml) and streptomycin $(100 \mathrm{mg} / \mathrm{ml})$. Cells were maintained in a $37^{\circ} \mathrm{C}$ humidified incubator supplying $5 \% \mathrm{CO}_{2}$.

Diet-induced obesity model. Three- to five-week-old male C57BL/6j mice (Slac Laboratory Animal, Shanghai, China) were weaned on a high-fat diet $(35.5 \%$ fat, $36.3 \%$ carbohydrate, $20.0 \%$ protein) and normal chow (5.4\% fat, $51.0 \%$ carbohydrate, $22.9 \%$ protein) (30), respectively, for 12 weeks. Then, 24/24 mice on the normal fat diet were referred to as 'lean', 24/36 animals consuming the high fat diet and chosen by the criterion that the body weight exceeded the mean plus 2 -fold standard deviation (SD) of the lean mice body weight were referred to as 'obese', and the other 12 mice on the high fat diet were referred to as 'non-obese'.

In vivo gastric cancer model. To detect the impact of obesity on tumor growth, 12 obese, 12 lean and 12 non-obese mice were injected subcutaneously with $2.0 \times 10^{6} \mathrm{MFC}$ cells into the right flank and monitored daily to check for the presence of palpable tumors. Another 12 obese and 12 lean mice which had no difference with relative injected mice in the body weight were injected subcutaneously with $0.9 \%$ normal saline into the right flank as a control group. Then, all mice were maintained on a normal or a high fat diet for another 2 weeks, respectively. Once tumors became palpable, tumor volume was calculated by measuring the length, width of the tumor with calipers as $1 / 2$ (length $x$ width ${ }^{2}$ ).

All experiments were performed with the approval of the Xi'an Jiaotong University Institutional Animal Care and Use Committee following the principles of laboratory animal care (NIH publication no. 85-23, revised 1985). All surgery was performed under sodium pentobarbital anesthesia and all efforts were made to minimize suffering.

Immunohistochemical staining. Tumors were collected and prepared for formalin-fixed, paraffin embedded tumor sections. The tumor sections were dewaxed and dehydrated. Rehydration, antigen retrieval in citrate buffer, endogenous peroxidase activity was blocked for 10 min using $3.0 \%$ hydrogen peroxide, the sections were blocked with $10 \%$ goat plasma for $30 \mathrm{~min}$, then separately incubated with the primary antibodies directed against iNampt, Sirt1 and c-MYC at $4^{\circ} \mathrm{C}$ overnight. The primary antibodies were detected using biotinylated secondary antibodies (Zhongshan Goldenbridge Biotechnology Co. Ltd., China) following the manufacturer's recommendations. The staining of the sections was performed using the HRP-streptavidin conjugates for iNampt, Sirt1 and c-MYC (SP method).

The staining results for iNampt, Sirt1 and c-MYC were semi-quantitatively expressed by an immunohistochemical score combined with the percentage of MFC cells showing specific immunoreactivity. Staining intensity was expressed as four grades: 0 , none; 1 , weak; 2, moderate; and 3, strong. The percentage of positive MFC cells was expressed as: $0,<5 \%$; $1,6-25 \% ; 2,26-50 \% ; 3,51-75 \%$; and $4,>75 \%$. The staining intensity and average percentage of positive MFC cells were assayed for 10 independent high power fields (x400). The total score was calculated by multiplying the staining intensity and the percentage of positive MFC cells. Sections with a total score of $>1$ were defined as exhibiting positive staining for the above proteins. All histological analyses were performed by three independent observers. The primary antibodies recognizing iNampt, Sirt1 and c-MYC and were purchased from Santa Cruz Biotechnology (Santa Cruz, CA, USA).

Serum assays. Mice were fasted overnight and sacrificed following anesthesia. Blood drawn from the retro-orbital venous plexus was preserved for analysis of metabolites. Enzyme-linked immunosorbent assay (ELISA) was used to determine serum concentration of insulin (Crystal Chem, Inc., Downers Grove, IL, USA) and visfatin (Linco Research, Inc., St. Charles, MO, USA) following the manufacturer's protocol. Serum glucose was determined by colorimetric assay.

Cellular proliferation assay. Cellular proliferation was evaluated by the 3-(4,5-dimethylthiazol-2-yl)-2,5-diphenyltetrazolium bromide (MTT) assay. MTT and dimethyl sulfoxide (DMSO) were obtained from Sigma Chemical. After exposure to RPMI-1640 or 5\% sera of obese or lean mice, MFC cells were incubated with $0.5 \% \mathrm{MTT}$ solution at $37^{\circ} \mathrm{C}$ for another $4 \mathrm{~h}$. Subsequently, $150 \mu \mathrm{l}$ of DMSO was added to solubilize 
the MTT tetrazolium crystal. Finally, the optical density was determined at $490 \mathrm{~nm}$ by a Benchmark Plus microplate reader (Bio-Rad, Hercules, CA, USA). All experiments were repeated in triplicate.

Cell migration assay. To detect the invasiveness of MFC cells in response to exposure to sera from obese or lean mice, we measured the ability of cell migration. Briefly, $5 \times 10^{4} \mathrm{MFC}$ cells suspended in serum-free RPMI-1640 were added to the top wells of migration chambers. The lower chambers were filled with $5 \%$ sera obtained from obese or lean mice, or serum-free RPMI-1640, and the top chambers were placed in 24-well plates and incubated for $24 \mathrm{~h}$ at $37^{\circ} \mathrm{C}$. After removal of the cells from the upper surface of the filters, the remaining cells on the lower surface were counted randomly in 10 different low-power fields (original magnification, x40) using a microscope.

Cellular apoptosis analysis. To determine phosphatidylserine externalization (on the surface of cell membrane), an indicator of early apoptosis, flow cytometry was performed with propidium iodide (PI) and fluorescein isothiocyanate (FITC)labeled Annexin V (Joincare Biosciences, Zhuhai, China) (31). After exposure to RPMI-1640 or 5\% sera of obese or lean mice for $24 \mathrm{~h}$, the remaining intact MFC cells were collected and $500 \mu \mathrm{l}$ of $1 \mathrm{X}$ binding buffer, $10 \mu \mathrm{l}$ of PI staining solution and $5 \mu \mathrm{l}$ of FITC-labeled Annexin V were added to them, and mixed well incubating at room temperature for $10 \mathrm{~min}$ in the dark. The cells were then analyzed for cell apoptosis on a FACScan (BD Biosciences, USA).

Cell cycle analysis. After exposure to RPMI-1640 or 5\% sera of obese or lean mice for $24 \mathrm{~h}$, MFC cells were harvested and resuspended at $1-5 \times 10^{5}$ cells $/ \mathrm{ml}$ with PBS. Aliquot $1 \mathrm{ml}$ cells were added into $3 \mathrm{ml}$ cold $\left(-20^{\circ} \mathrm{C}\right)$ absolute ethanol and fixed overnight at $-20^{\circ} \mathrm{C}$, then washed with PBS. Following centrifugation at $1500 \mathrm{rpm}$ for $5 \mathrm{~min}, 1 \mathrm{ml} \mathrm{PI}$ and $50 \mu \mathrm{l}$ RNase A stock solution were added to the cell pellet and mixed gently. After incubation at $25^{\circ} \mathrm{C}$ for $30 \mathrm{~min}$ in the dark, the cells were analyzed for cell cycle on a FACScan (BD Biosciences).

RNA expression studies. After exposure to RPMI-1640 or 5\% sera of obese or lean mice for $24 \mathrm{~h}$, total RNA was extracted from the cultured cells with the TRIzol reagent (Invitrogen, San Diego, CA, USA), then reverse transcribed to cDNA with High Capacity 1st Strand Synthesis kit (Takara Biochemicals, Japan). The cycling program was based on the manufacturer's instructions. Expression of nampt, sirtl and $c$-myc mRNA was quantified by RT-PCR (Takara Biochemicals). Transcript levels were normalized to $\beta$-actin. Briefly, the reaction was carried out using an Icycler (Bio-Rad) with the following thermal profile: a pre-heating step at $95^{\circ} \mathrm{C}$ for $10 \mathrm{~min}$ followed by 30 repeats of $94.0^{\circ} \mathrm{C}$ for $30 \mathrm{sec}$ and $55.0^{\circ} \mathrm{C}$ for $30 \mathrm{sec}$, then $72^{\circ} \mathrm{C}$ for $1 \mathrm{~min}$. The primer sequences were generated using NCBI primer-BLAST. Murine $\beta$-actin was amplified using forward primer 5'-TTCTTTGCAGCTCCTTCGTTGCCG-3' and reverse primer 5'-TGGATGGCTACGTACATGGCTGGG-3' (NM 007393.3), which yielded a product of $467 \mathrm{bp}$. Murine nampt was amplified using forward primer 5'-TCGGTTC TGGTGGCGCTTTGCTAC-3' and reverse primer 5'-AAG
TTCCCCGCTGGTGTCCTATGT-3' (NM 021524.2), which yielded a product of $181 \mathrm{bp}$. Murine sirtl was amplified using forward primer 5'-TTGTGAAGCTGTTCGTGGAG-3' and reverse primer 5'-GCGTGGAGGTTTTTCAGTA-3' (NM 001159590.1), which yielded a product of $412 \mathrm{bp}$. Murine $c$-myc was amplified using forward primer 5'-CAGCGACTCT GAAGAAGAGCAAG-3' and reverse primer 5'-GGGTTT GCCTCTTCTCCACAG-3' (NM 001177354.1), which yielded a product of $71 \mathrm{bp}$. For validation, each experiment was performed in triplicate.

Protein extraction and western blot analysis. We examined the expression of iNampt, Sirt1 and c-MYC in the cultured cells with exposure to RPMI-1640 or 5\% sera of obese mice or lean animals to detect whether obesity may be responsible for the growth of MFC cells. After treatment for $24 \mathrm{~h}$, cells were lysed in RIPA buffer on ice. Protein concentration was measured via the BCA method (Pierce), bromophenol blue and NuPage Reducing Agent (Invitrogen) were added to the lysate, and the final mixture was heated. Equal amounts of total protein were run on a $10 \%$ SDS-PAGE and were electrotransferred onto nitrocellulose membranes (Millipore, Bedford, MA, USA) using a Bio-Rad Mini PROTEAN 3 System according to the standard protocol. The nitrocellulose membranes were then blocked in TBST with $5 \%$ non-fat dry milk at $37^{\circ} \mathrm{C}$ for $2 \mathrm{~h}$. Subsequently, the membranes were incubated with a 1:200 dilution of the primary antibodies for iNampt, Sirt1 and c-MYC, and a 1:2,000 dilution of anti- $\beta$-actin at $4^{\circ} \mathrm{C}$ overnight. An antibody against rabbit $\operatorname{IgG}$ was used as the secondary antibody. The membranes were developed with enhanced chemiluminescence (Pierce) by an enhanced chemiluminescence detection system (Amersham Biosciences, Piscataway, NJ, USA). The primary antibodies recognizing iNampt, Sirt1, c-MYC and $\beta$-actin were purchased from Santa Cruz Biotechnology.

Statistical analysis. Values are expressed as the mean \pm SD. Statistical differences were estimated by one-way analysis of variance (ANOVA) followed by Dunnett's test or the Spearman rank test. P-value $<0.05$ was considered to indicate statistically significant differences. Analysis of the data and plotting of the figures were performed with the aid of software (SPSS version 13.0).

\section{Results}

Metabolic changes in obese mice and their effects on tumor growth. Obese, non-obese and lean mice were selected and used as recipients of MFC cells to determine the influence of obesity on gastric cancer growth. At the time of transplantation, the lean mice (body weight, $28.5 \pm 1.2 \mathrm{~g}, \sim 26.5-30.5 \mathrm{~g}$ ) were significantly lighter than the obese mice $(35.4 \pm 2.8 \mathrm{~g}$, 32.0-40.5g) $(\mathrm{P}<0.05)$, and had no difference with non-obese mice $(28.7 \pm 2.3 \mathrm{~g}, \sim 26.0-31.0 \mathrm{~g})(\mathrm{P}>0.05)$.

No mouse died and no metastasis was detected during the experimental time frame. The tumors became palpable 4 days after injection and tumor growth was detected in $83.3 \%(10 / 12)$ of the lean mice, in $75 \%(9 / 12)$ of the non-obese mice and in $100 \%(12 / 12)$ of the obese animals. Tumors grew faster in the obese mice than in the lean and non-obese animals within 


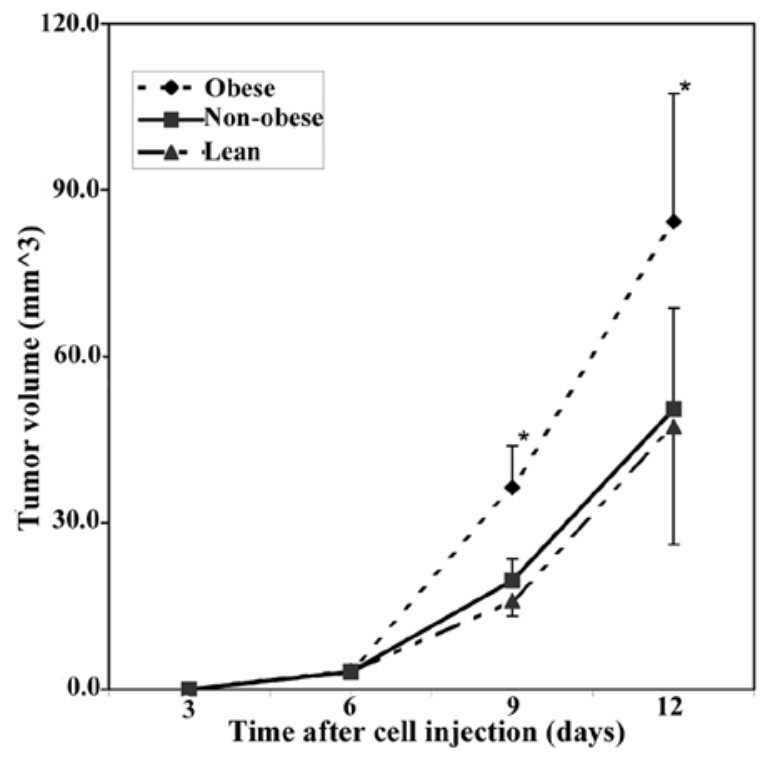

Figure 1. Subcutaneous tumor growth curve. Tumors from obese mice grew faster than those from lean and non-obese animals within 2 weeks. ${ }^{*} \mathrm{P}<0.05$ vs. lean and non-obese mice.

2 weeks (Fig. 1). Then, all mice were sacrificed and the tumors were collected. The tumor weights were: lean, $77.2 \pm 14.9 \mathrm{mg}$ $(\mathrm{P}<0.01$ vs. obese and $\mathrm{P}>0.05$ vs. non-obese); non-obese, $83.4 \pm 15.3 \mathrm{mg}(\mathrm{P}<0.01 \mathrm{vs}$. obese); obese, $134.2 \pm 17.3 \mathrm{mg}$, and showed a significantly positive correlation with the body weight of the mice $(r=0.75, \mathrm{P}<0.05)$.

There was no difference between injected mice and relative control group animals in the body weight, serum glucose, insulin and visfatin concentrations. The obese mice with insulin resistance and glucose intolerance (28) were hyperglycemic, hyperinsulinemic, and had high serum visfatin concentration (Table I). The tumor weights correlated significantly with serum visfatin concentration $(\mathrm{r}=0.47, \mathrm{P}<0.05)$ and insulin level $(\mathrm{r}=0.37, \mathrm{P}<0.05)$, but did not correlate with serum glucose concentration $(\mathrm{r}=0.22, \mathrm{P}>0.05)$. This indicated that obesity may promote murine gastric cancer growth by endocrine mechanisms.

Expression of iNampt, Sirtl and c-MYC in the tumors and their correlation. The mechanisms by which obesity affects gastric cancer growth remain unclear. We considered the possibility that obesity prompts gastric cancer growth by the new pro-survival signal, nampt/sirtl/c-myc positive feedback loop. Therefore, we investigated the expression of these related genes nampt, sirtl and $c$-myc in the subcutaneous tumors by immunohistochemical staining which might be altered in the context of obesity. The protein expression of iNampt, Sirt1 and c-MYC was assessed semi-qualitatively by immunohistochemical analysis. iNampt protein expressed in the cytoplasm and nucleus, Sirt1 and c-MYC proteins localized mainly in the nucleus were significantly elevated in the tumors from obese mice than in those from lean mice $(\mathrm{P}<0.01)$ (Figs. 2-4). Additionally, the level of iNampt protein was positively correlated with that of $\mathrm{c}-\mathrm{MYC}(\mathrm{r}=0.54, \mathrm{P}=0.01)$ and Sirt1 $(\mathrm{r}=0.71, \mathrm{P}<0.001)$ in the tumors, and Sirt1 protein expression was positively correlated with c-MYC $(r=0.43$,
Table I. Serum metabolic changes in mice.

\begin{tabular}{lccc}
\hline & \multicolumn{3}{c}{ Groups } \\
\cline { 2 - 4 } Parameters & Obese & Non-obese & Lean \\
\hline Visfatin $(\mathrm{ng} / \mathrm{ml})$ & $44.3 \pm 3.6^{\mathrm{a}}$ & $38.9 \pm 2.7^{\mathrm{b}}$ & $39.6 \pm 3.4$ \\
Insulin $(\mathrm{ng} / \mathrm{ml})$ & $0.51 \pm 0.07^{\mathrm{a}}$ & $0.41 \pm 0.03^{\mathrm{b}}$ & $0.40 \pm 0.04$ \\
Glucose $(\mathrm{mmol} / \mathrm{l})$ & $11.9 \pm 1.6^{\mathrm{a}}$ & $8.1 \pm 2.0^{\mathrm{b}}$ & $7.8 \pm 1.6$
\end{tabular}

${ }^{\mathrm{a}} \mathrm{P}<0.05$ vs. lean and non-obese, ${ }^{\mathrm{b}} \mathrm{P}>0.05$ vs. lean.

Table II. Cell cycle in MFC cells over various culture conditions for $24 \mathrm{~h}$.

\begin{tabular}{lccc}
\hline Group & $\begin{array}{c}\mathrm{G} 0 / \mathrm{G} 1 \\
(\text { mean } \pm \mathrm{SD}, \%)\end{array}$ & $\begin{array}{c}\mathrm{S} \\
(\text { mean } \pm \mathrm{SD}, \%)\end{array}$ & $\begin{array}{c}\mathrm{G} 2 / \mathrm{M} \\
(\text { mean } \pm \mathrm{SD}, \%)\end{array}$ \\
\hline Obese & $70.88 \pm 1.53^{\mathrm{a}}$ & $6.40 \pm 0.84^{\mathrm{a}}$ & $22.72 \pm 1.03$ \\
Lean & $78.34 \pm 2.18$ & $0.18 \pm 0.19$ & $21.47 \pm 2.06$ \\
RPMI-1640 & $77.60 \pm 2.49$ & $0.25 \pm 0.27$ & $22.15 \pm 2.34$ \\
\hline
\end{tabular}

${ }^{\mathrm{a}} \mathrm{P}<0.05$ vs. lean group.

$\mathrm{P}=0.02<0.05$ ), as assessed by the Spearman rank test. Of note, iNampt protein expression in these tumors was positively correlated with serum visfatin $(\mathrm{r}=0.76, \mathrm{P}<0.001)$ and insulin concentrations $(\mathrm{r}=0.39, \mathrm{P}=0.02<0.05)$, but not with fasting glucose level $(\mathrm{r}=0.12, \mathrm{P}>0.05)$.

Effects of obesity on tumor cell migration and proliferation. Individual cell migration is an important characteristic of invasive tumor cells, therefore we examined the effects of obesity on modulating cell migration. The migrating cell quantity of the obesity group was significantly larger than that of the lean group in the low-power fields (original magnification, $\mathrm{x} 40$ )

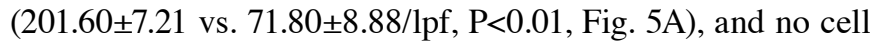
migration existed in the RPMI-1640 group. It was apparent that obesity induced the ability of MFC cells traversing the filter to a highly significant degree.

In this study, we also used MTT assay to assess MFC cell proliferation. These groups were as follows: obesity, lean, and RPMI-1640 as the control group. After treatment, cell proliferation by MTT assay was followed over a course of 5 days. The results of cell growth curve assay showed that obesity prompted MFC cell growth significantly faster compared to the lean group (Fig. 5B), and obesity also promoted MFC proliferation in the subcutaneous tumors by DNA incorporation of 5-bromodeoxyuridine (5-Brdu) in our previous study (28).

Effects of obesity on tumor cell cycle and apoptosis. To further explore how obesity promoted gastric cancer cell survival and growth, we assessed MFC cell cycle and apoptotic status using FACS analysis after treatment for $24 \mathrm{~h}$. The apoptosis assay results indicated that the average rate of apoptosis in the Annexin V-positive (apoptosis portion) area in obesity, lean and RPMI-1640 group was $24.59 \pm 3.26 \%, 43.21 \pm 5.21 \%$ 

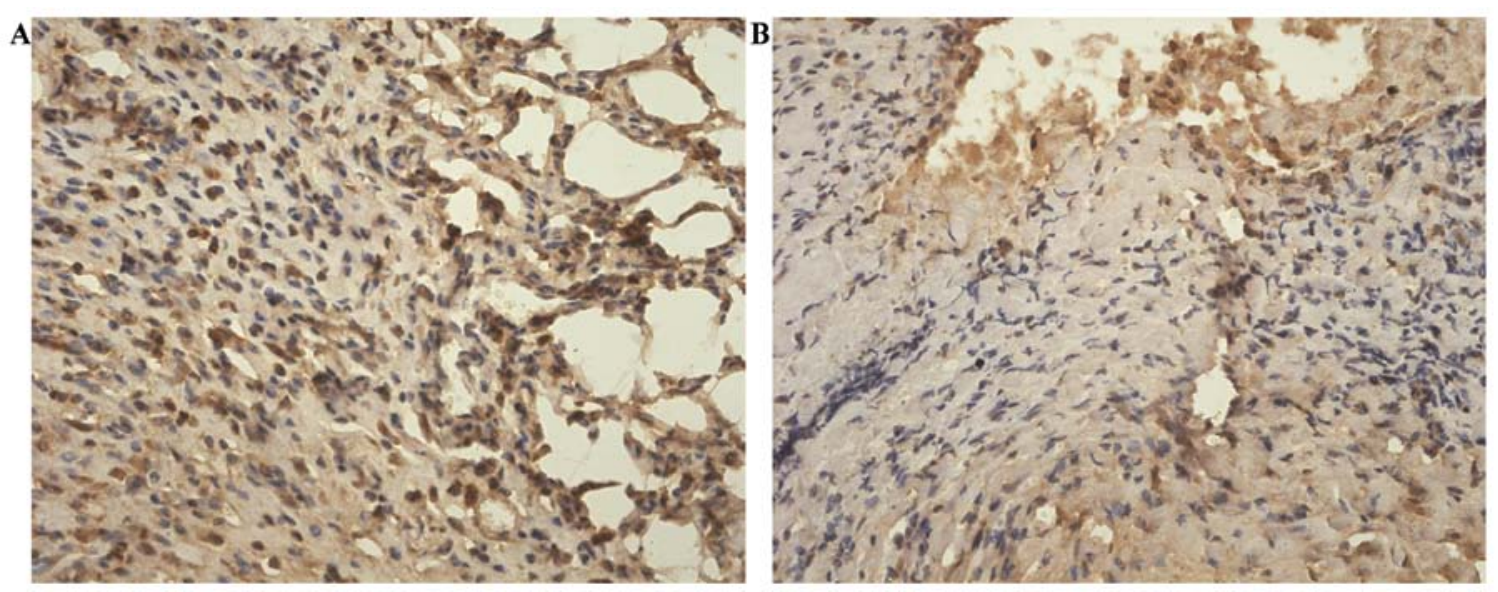

Figure 2. The protein expression of iNampt in the subcutaneous tumors was analyzed. iNampt protein expression was significantly higher in the tumors from obese mice (A) than in those from lean animals (B) by immunohistochemical staining $(5.70 \pm 0.22$ vs. $1.20 \pm 0.39, \mathrm{P}<0.001)$.
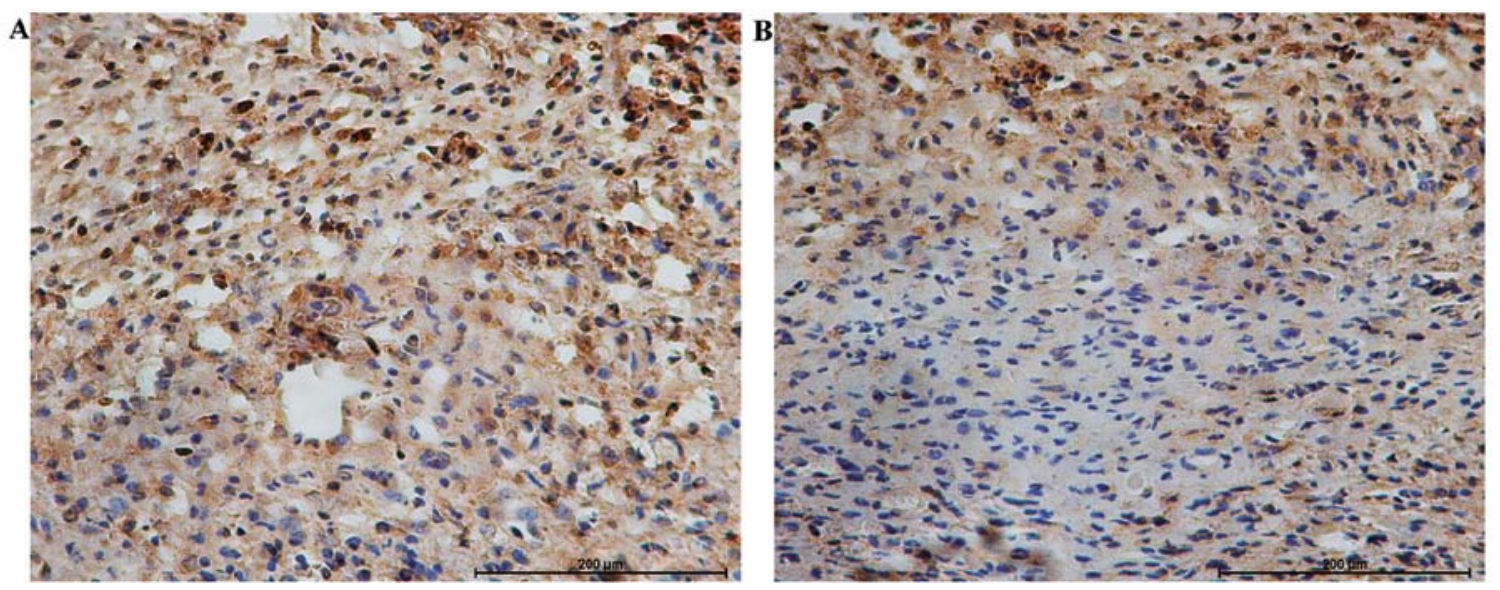

Figure 3. Sirt1 protein expression in the subcutaneous tumors was evaluated. The protein expression of Sirt1 was significantly elevated in the tumors from obese mice (A) compared to those from lean mice (B) by immunohistochemical staining ( $7.15 \pm 0.72$ vs. $1.58 \pm 0.23, \mathrm{P}=0.013$ ).
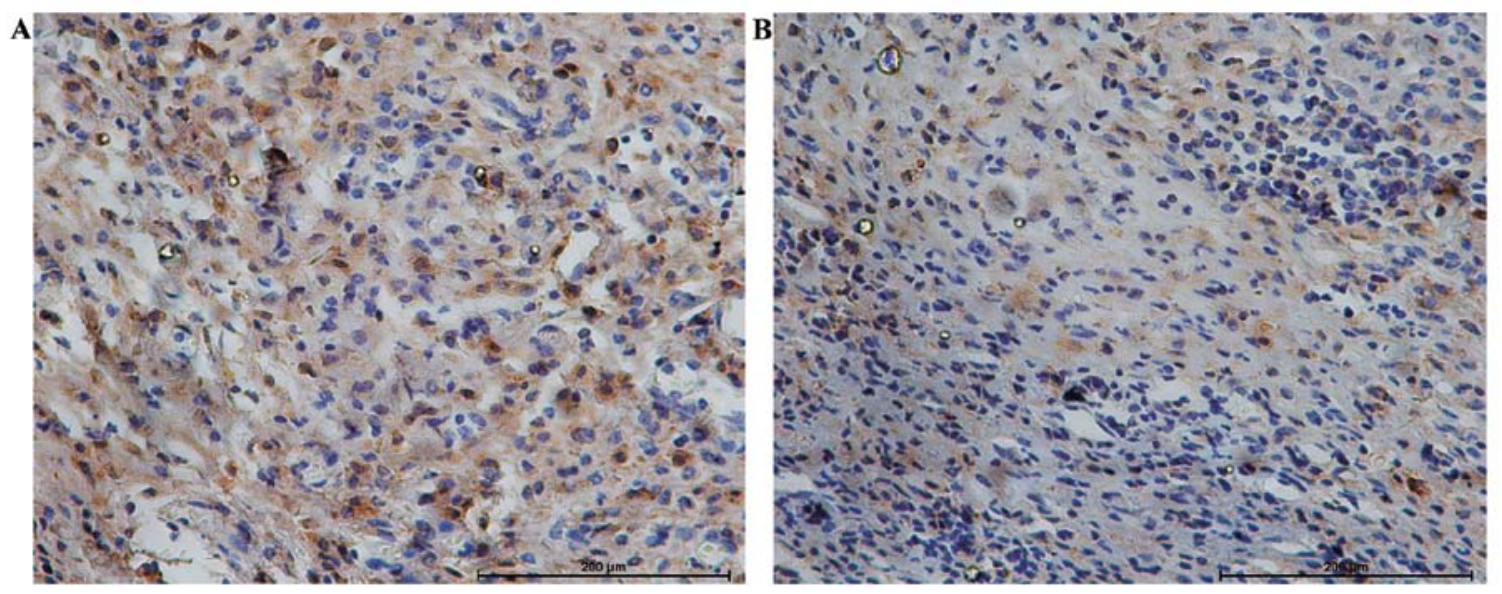

Figure 4. The expression of c-MYC protein in the tumors was also assessed semi-qualitatively. c-MYC protein expression significantly increased in the subcutaneous tumors from obese mice (A) compared to those from lean animals (B) by immunohistochemical analysis $(3.70 \pm 0.67$ vs. $0.8 \pm 0.29$, $\mathrm{P}<0.001)$.

and $57.10 \pm 4.55 \%$, respectively, and there was a statistically significant difference between the obesity and the lean group $(\mathrm{P}<0.05$, Fig. 6). It appeared that obesity had an important influence on prompting MFC cell survival and decreasing the cell apoptosis, and this was verified in the subcutaneous tumors by TUNEL assay in our previous study (28). 
A

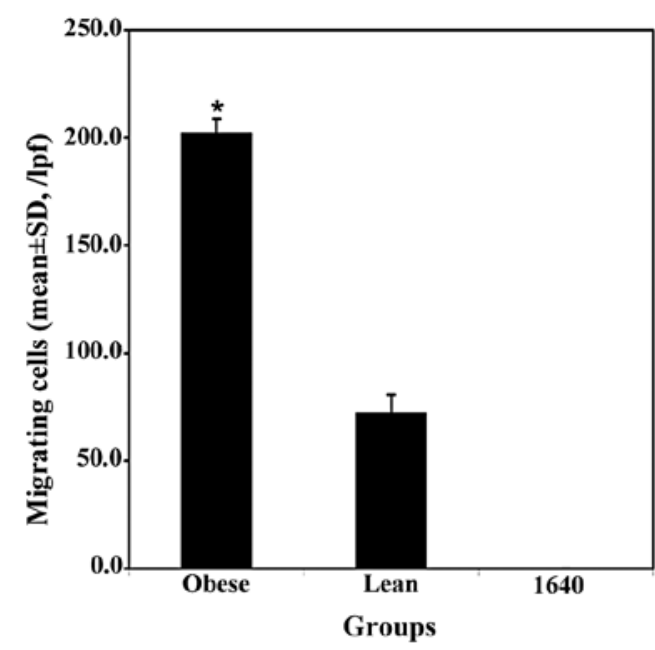

B

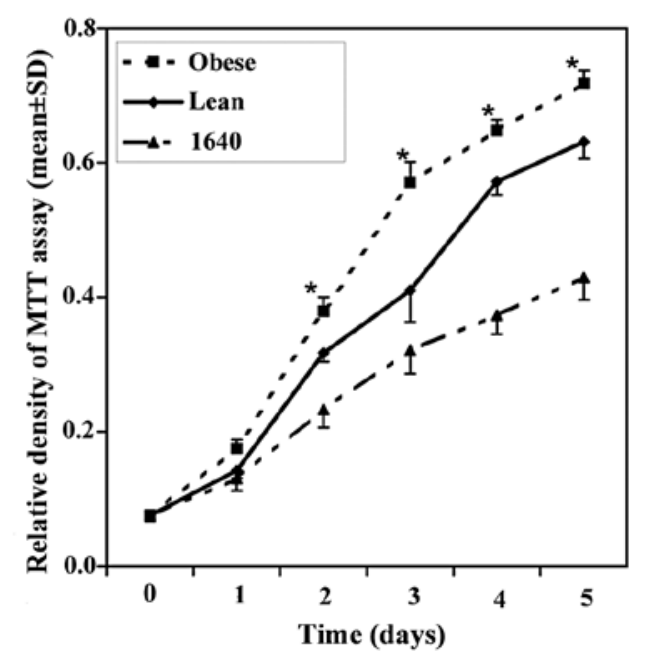

Figure 5. Effects of obesity on tumor cell migration and proliferation. (A) Obesity significantly potentiated MFC cell migration compared to the lean group (201.60 \pm 7.21 vs. $\left.71.80 \pm 8.88 / \mathrm{lpf},{ }^{*} \mathrm{P}<0.05\right)$. (B) Obesity prompted MFC cell growth significantly faster compared to the lean group ( $\mathrm{P}<0.05)$.

The data of cell cycle analysis showed that obesity played a key role in cell cycle progression, and obesity significantly increased $\mathrm{S}$ phase $(\mathrm{P}<0.05)$ and decreased $\mathrm{G} 0 / \mathrm{G} 1$ phase $(\mathrm{P}<0.05)$; however, it had no influence on $\mathrm{G} 2 / \mathrm{M}$ phase (Table II). This demonstrated that obesity accelerated cell cycle progression.

Obesity promotes the growth of gastric cancer by nampt/ sirt1/c-myc positive feedback loop. For validation, we also investigated the expression of these related genes nampt, sirtl and c-myc in the cultured MFC cells which might be altered in the context of obesity. Obesity significantly upregulated iNampt, Sirtl and c-MYC protein expression of MFC cells (Fig. 7A and B), and these results were verified at the mRNA level by RT-PCR (Fig. 7C and D). This showed that obesity could potentiate MFC cell migration and proliferation, decrease MFC cellular apoptosis, and accelerate cell cycle progression including endocrine mechanisms.
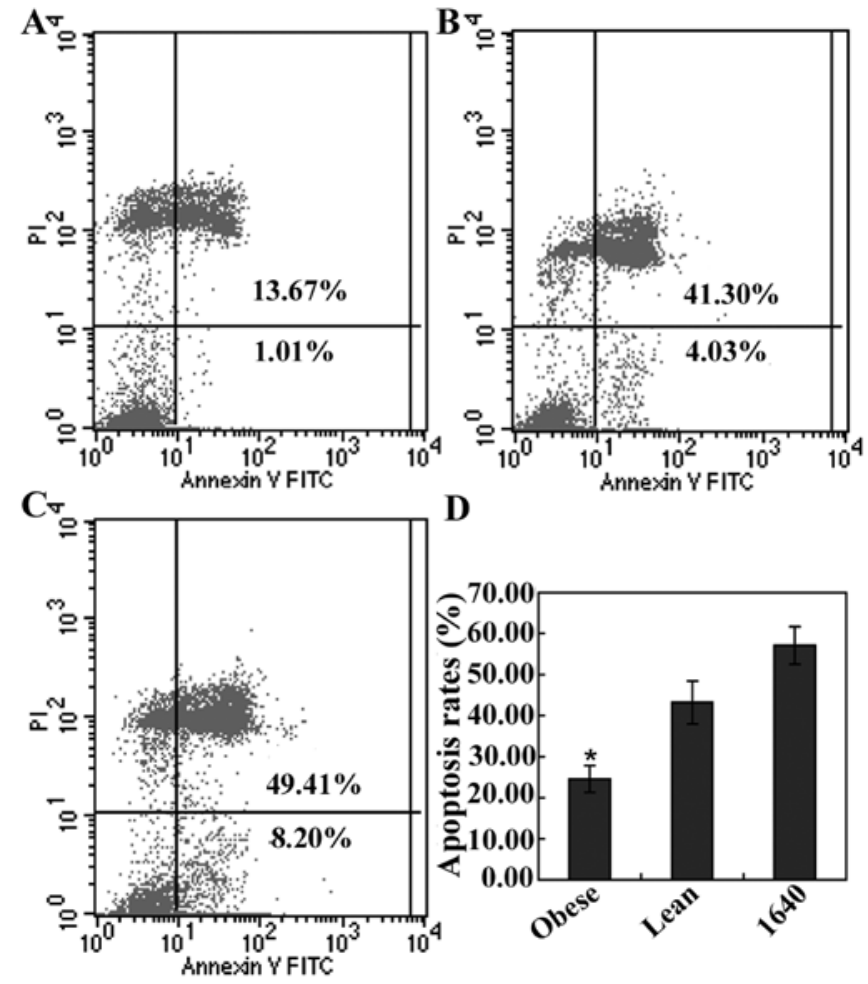

D

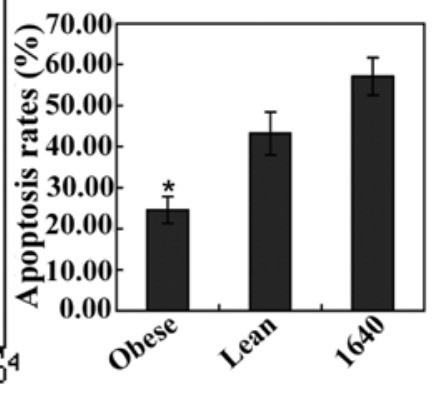

Figure 6. Effects of obesity on tumor cell apoptosis. The average rate of apoptosis in the Annexin V-positive (apoptosis portion) area in obese (A), lean (B) and RPMI-1640 group (C) was 24.59 $\pm 3.26,43.21 \pm 5.21$ and $57.10 \pm 4.55 \%$, respectively, and there was a statistically significant difference between the obese and the lean group $\left({ }^{*} \mathrm{P}<0.05\right)$.

\section{Discussion}

Elucidating the mechanisms linking obesity and gastric cancer is complicated due to the numerous biological effects of obesity. Therefore, we developed a gastric cancer in vivo model and cell culture in vitro utilizing the sera of mice to explore this correlation. The results demonstrated that MFC cells survived longer and grew larger in obese C57BL/6j mice compared to non-obese and lean animals within 2 weeks, which strongly indicated a positive correlation between obesity and tumor growth. Additionally, the effect of obesity was not affected by the high fat diet. Our previous histological data revealed that injected tumors were surrounded by adipocytes and fat depots were also detected within the tumors, which suggested that the adipocyte microenvironment might be a protective niche for MFC cell survival and growth, although the microvessel density was not significantly different between the lean and the obese groups (28). This is consistent with the hypothesis that adipose tissue plays a protective role in the microenvironment of breast cancer (32), colon cancer (33) and multiple myeloma (34).

This study also showed that obesity potentiated MFC cell migration and proliferation, decreased MFC cellular apoptosis, and accelerated cell cycle progression through endocrine mechanisms. Obesity increased the expression levels of pro-survival signals, which may shift the apoptotic balance of MFC toward survival. The main targets of this obesity-mediated effect are probably the nampt/sirtl/c-myc positive feedback loop. Their expression in MFC cells was upregulated at the mRNA and protein levels in the context of obesity which could prompt 
A

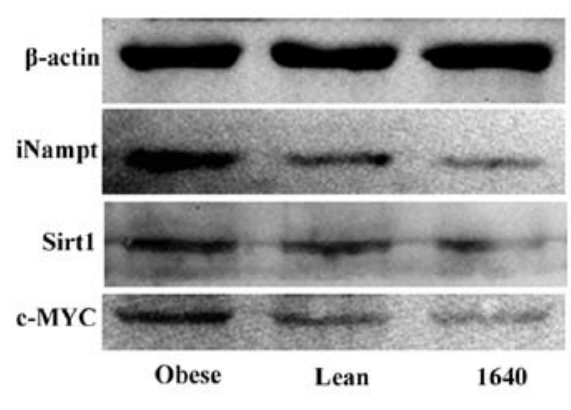

C

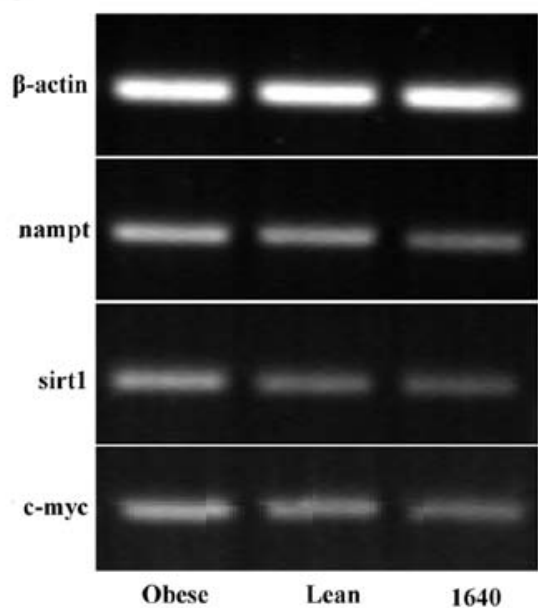

B

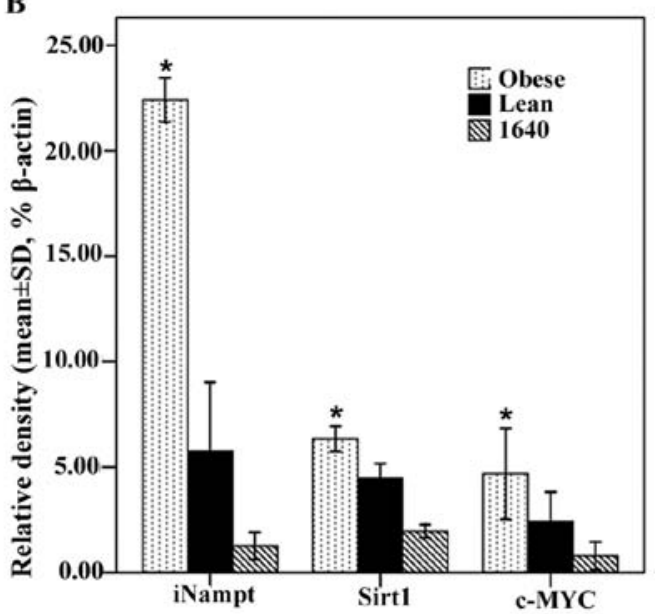

D

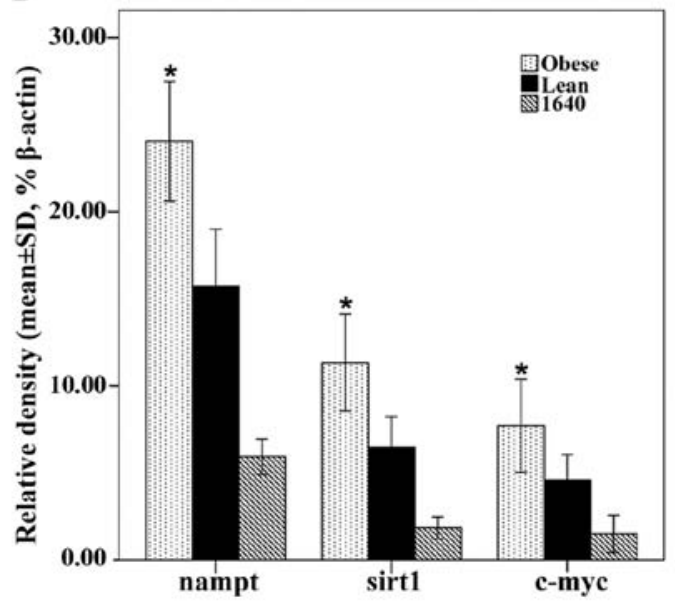

Figure 7. The mechanism underlying the promotion of murine gastric cancer cell growth by diet-induced obesity. Obesity promotes the growth of murine gastric cancer cells by a nampt/sirtl/c-myc positive feedback loop at the protein level by western blotting (A and B) and at the mRNA level by RT-PCR (C and D) $(\mathrm{P}<0.05)$.

gastric cancer survival and growth. However, it is unclear which specific adipose depots are relevant to MFC cell growth.

White adipose tissue, considered to be an inert tissue as an energy store, drew more attention for secreting a great number of adipokines in the past years. Adipokines secreted mainly by adipocytes are small, biologically active factors which could play an important role in stimulating tumor development. Adipokines including resistin, leptin and adiponectin are implicated in cell growth, proliferation, cell cycle control and angiogenesis (35).

The new adipokine, visfatin, may facilitate tumor proliferation and metastasis in various types of cancer including breast $(36,37)$ and prostate cancer $(38)$. In addition, it was reported that circulating visfatin concentrations correlated with tumor progression in malignant astrocytomas (39), gastric cancer (40), and colorectal cancer (41). This study demonstrated directly the correlation between gastric cancer growth and visfatin. Visfatin, also acting as an NAD biosynthetic enzyme similar to iNampt, catalyzes the transfer of a phosphoribosyl group from 5-phosphoribosyl-1-pyrophosphate to nicotinamide, forming nicotinamide mononucleotide (NMN) and pyrophosphate (16). NMN is then converted to NAD by nicotinamide mononucleotide adenylyltransferase (Nmnat) $(42,43)$ through the $\mathrm{NAD}^{+}$salvage pathway.
We previously demonstrated that iNampt was overexpressed in gastric cancer, and the specific iNampt inhibitor FK866 suppressed gastric cancer cell proliferation and growth (15). As such, visfatin enriched in obesity may promote gastric cancer development by functioning as an NAD biosynthetic enzyme similar to iNampt in the $\mathrm{NAD}^{+}$salvage pathway to increase $\mathrm{NAD}^{+}$content, which directly affects the ability of Sirt1 or by other ways, then activates c-MYC, iNampt and Sirt1 to form a positive feedback loop. Insulin may also influence obesity-mediated tumor development through insulin receptor A isoform (IR-A), IR-B, and heterodimeric receptors including IGF-IR and IR (44), then stimulating downstream activation of AKT and MAPK and prompting cancer cell proliferation (30). The novel findings of this study that serum visfatin and insulin concentrations were positively correlated with the subcutaneous tumor growth and the expression of iNampt protein in the tumors was consistent with the notion that adipokines and other growth factors secreted in the context of obesity may enhance cancer cell survival and solid tumor growth.

In conclusion, this study clearly revealed that obesity potentiated transplanted tumor growth in mice, promoted gastric cancer cell migration, proliferation and survival, and increased cell cycling in vitro. These were correlated with the elevated expression levels of nampt, sirt1 and $c-m y c$. 


\section{Acknowledgements}

The authors thank Dr Hai-Tao Shi, from the GI Medicine Department of the Second Affiliated Hospital and the Institution of Genetic Disease Research of Xi'an Jiaotong University, for his technical assistance. This study was supported by a grant from the National Natural Science Foundation of China (no. 81172357).

\section{References}

1. Brenner H, Rothenbacher D and Arndt V: Epidemiology of stomach cancer. Methods Mol Biol 472: 467-477, 2009.

2. David MR: The epidemiology of gastric cancer. Gastric Cancer 5: 5-11, 2002

3. Jemal A, Bray F, Center MM, Ferlay J, Ward E and Forman D: Global cancer statistics. CA Cancer J Clin 61: 69-90, 2011.

4. Flegal KM, Carroll MD, Kit BK and Ogden CL: Prevalence of obesity and trends in the distribution of body mass index among US adults, 1999-2010. JAMA 307: 491-497, 2012.

5. El-Serag HB: Obesity and disease of the esophagus and colon. Gastroenterol Clin North Am 34: 63-82, 2005.

6. Whiteman MK, Hillis SD, Curtis KM, McDonald JA, Wingo PA and Marchbanks PA: Body mass and mortality after breast cancer diagnosis. Cancer Epidemiol Biomarkers Prev 14: 2009-2014, 2005 .

7. Crew KD and Neugut AI: Epidemiology of gastric cancer. World J Gastroenterol 12: 354-362, 2006.

8. Yang P, Zhou Y, Chen B, Wan HW, Jia GQ, Bai HL and Wu XT: Overweight, obesity and gastric cancer risk: results from a metaanalysis of cohort studies. Eur J Cancer 45: 2867-2873, 2009.

9. Zhang Y, Daquinag A, Traktuev DO, et al: White adipose tissue cells are recruited by experimental tumors and promote cancer progression in mouse models. Cancer Res 69: 5259$5266,2009$.

10. Samal B, Sun Y, Stearns G, Xie C, Suggs S and McNiece I: Cloning and characterization of the cDNA encoding a novel human pre-B-cell colony-enhancing factor. Mol Cell Biol 14 1431-1437, 1994.

11. Fukuhara A, Matsuda M, Nishizawa M, et al: Visfatin: a protein secreted by visceral fat that mimics the effects of insulin. Science 307: 426-430, 2005.

12. Bi TQ and Che XM: Nampt/PBEF/visfatin and cancer. Cancer Biol Ther 10: 119-125, 2010.

13. Van Beijnum JR, Moerkerk PT, Gerbers AJ, De Bruïne AP, Arends JW, Hoogenboom HR and Hufton SE: Target validation for genomics using peptide-specific phage antibodies: a study of five gene products overexpressed in colorectal cancer. Int J Cancer 101: 118-127, 2002.

14. Folgueira MA, Carraro DM, Brentani $\mathrm{H}$, et al: Gene expression profile associated with response to doxorubicin-based therapy in breast cancer. Clin Cancer Res 11: 7434-7443, 2005.

15. Bi TQ, Che XM, Liao XH, Zhang DJ, Long HL, Li HJ and Zhao W: Overexpression of Nampt in gastric cancer and chemopotentiating effects of the Nampt inhibitor FK866 in combination with fluorouracil. Oncol Rep 26: 1251-1257, 2011.

16. Revollo JR, Grimm AA and Imai S: The regulation of nicotinamide adenine dinucleotide biosynthesis by Nampt/PBEF/ visfatin in mammals. Curr Opin Gastroenterol 23: 164-170, 2007.

17. Voelter-Mahlknecht S and Mahlknecht U: Cloning, chromosomal characterization and mapping of the NAD-dependent histone deacetylases gene sirtuin 1. Int J Mol Med 17: 59-67, 2006.

18. Luo J, Nikolaev AY, Imai S, et al: Negative control of p53 by Sir2alpha promotes cell survival under stress. Cell 107: 137-148, 2001.

19. Vaziri H, Dessain SK, Ng Eaton E, et al: hSIR2(SIRT1) functions as an NAD-dependent p53 deacetylase. Cell 107: $149-159,2001$

20. Kuzmichev A, Margueron R, Vaquero A, et al: Composition and histone substrates of polycomb repressive group complexes change during cellular differentiation. Proc Natl Acad Sci USA 102: 1859-1864, 2005.

21. Chen WY, Wang DH, Yen RC, Luo J, Gu W and Baylin SB: Tumor suppressor HIC1 directly regulates SIRT1 to modulate p53-dependent DNA-damage responses. Cell 123: 437-448, 2005.
22. Saunders LR and Verdin E: Sirtuins: critical regulators at the crossroads between cancer and aging. Oncogene 26: 5489-5504, 2007.

23. Lim CS: Human SIRT1: a potential biomarker for tumorigenesis? Cell Biol Int 31: 636-637, 2007.

24. Lüscher B and Vervoorts J: Regulation of gene transcription by the oncoprotein MYC. Gene 494: 145-160, 2012.

25. Eilers M and Eisenman RN: Myc's broad reach. Genes Dev 22: 2755-2766, 2008

26. Soucek L, Whitfield J, Martins CP, et al: Modelling Myc inhibition as a cancer therapy. Nature 455: 679-683, 2008.

27. Menssen A, Hydbring P, Kapelle K, et al: The c-MYC oncoprotein, the NAMPT enzyme, the SIRT1-inhibitor DBC1, and the SIRT1 deacetylase form a positive feedback loop. Proc Natl Acad Sci USA 109: E187-E196, 2012.

28. Li HJ, Che XM, Zhao W, He SC, Zhang ZL and Chen R: Dietinduced obesity potentiates the growth of gastric cancer in mice. Exp Ther Med 4: 615-620, 2012.

29. Qian SS, Gao J, Wang JX, Liu Y and Dong HY: Establishment of a mouse forestomach carcinoma cell line (MFC) with spontaneous hematogenous metastasis and preliminary study of its biological characteristics. Zhonghua Zhong Liu Za Zhi 9: 261-264, 1987 (In Chinese).

30. Yakar S, Nunez NP, Pennisi P, et al: Increased tumor growth in mice with diet-induced obesity: impact of ovarian hormones. Endocrinology 147: 5826-5834, 2006.

31. Vermes I, Haanen C, Steffens-Nakken H and Reutelingsperger C: A novel assay for apoptosis. Flow cytometric detection of phosphatidylserine expression on early apoptotic cells using fluorescein labelled Annexin V. J Immunol Methods 184: 39-51, 1995.

32. Iyengar P, Combs TP, Shah SJ, et al: Adipocyte-secreted factors synergistically promote mammary tumorigenesis through induction of anti-apoptotic transcriptional programs and protooncogene stabilization. Oncogene 22: 6408-6423, 2003.

33. Amemori S, Ootani A, Aoki S, et al: Adipocytes and preadipocytes promote the proliferation of colon cancer cells in vitro. Am J Physiol Gastrointest Liver Physiol 292: G923-G929, 2007.

34. Caers J, Deleu S, Belaid Z, et al: Neighboring adipocytes participate in the bone marrow microenvironment of multiple myeloma cells. Leukemia 21: 1580-1584, 2007.

35. Tilg $\mathrm{H}$ and Moschen AR: Adipocytokines: mediators linking adipose tissue, inflammation and immunity. Nat Rev Immunol 6: 772-783, 2006

36. Kim SR, Park HJ, Bae YH, et al: Curcumin down-regulates visfatin expression and inhibits breast cancer cell invasion. Endocrinology 153: 554-563, 2012.

37. Kim JG, Kim EO, Jeong BR, et al: Visfatin stimulates proliferation of MCF-7 human breast cancer cells. Mol Cells 30: 341-345, 2010.

38. Patel ST, Mistry T, Brown JE, Digby JE, Adya R, Desai KM and Randeva HS: A novel role for the adipokine visfatin/pre-B cell colony-enhancing factor 1 in prostate carcinogenesis. Peptides 31: 51-57, 2010

39. Reddy PS, Umesh S, Thota B, et al: PBEF1/NAmPRTase/ Visfatin: a potential malignant astrocytoma/glioblastoma serum marker with prognostic value. Cancer Biol Ther 7: 663-668, 2008.

40. Nakajima TE, Yamada Y, Hamano T, et al: Adipocytokine levels in gastric cancer patients: resistin and visfatin as biomarkers of gastric cancer. J Gastroenterol 44: 685-690, 2009.

41. Nakajima TE, Yamada Y, Hamano T, et al: Adipocytokines as new promising markers of colorectal tumors: adiponectin for colorectal adenoma, and resistin and visfatin for colorectal cancer. Cancer Sci 101: 1286-1291, 2010.

42. Garten A, Petzold S, Körner A, Imai S and Kiess W: Nampt: linking NAD biology, metabolism and cancer. Trends Endocrinol Metab 20: 130-138, 2009

43. Pilz S, Mangge H, Obermayer-Pietsch B and März W: Visfatin/ pre-B-cell colony-enhancing factor: a protein with various suggested functions. J Endocrinol Invest 30: 138-144, 2007.

44. Sciacca L, Costantino A, Pandini G, et al: Insulin receptor activation by IGF-II in breast cancers: evidence for a new autocrine/ paracrine mechanism. Oncogene 18: 2471-2479, 1998. 